a Pres

a Port

- Monı

Núm

Ante

Cont

I Indz

- Edici

- Infol

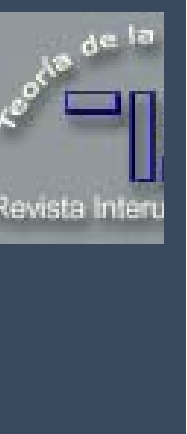

\section{Computer Based Training Authors' and Designers' training}

\author{
Frédéric Godet
}

\section{INTRODUCTION}

What is the most difficult discipline to teach in traditional education? One of the occidental countries' major education objectives is surely insuring children's ability to communicate, to practice correctly their mother tongue, to master the major means of representing an idea. A serious teachers' percent are ready to agree that verbal and written language represent one of the most difficult domain to teach. Including the University levels, all the training processes put an heavy emphasis on the competencies and performances of language practice. From an hypermedia or multimedia specialists' point of view, it represent only one of the expression means used in the multimedia works creation. Interactive multimedia modules authors and designers needs competencies and performances not only in several languages or code systems, but also in the expressing combination of them. Additionally, Computer Based Training - Interactive Multimedia Modules need high capacities in pedagogy and didactic domains.Our communication objectives trend to give an envelope of directions and advises to build training systems dedicated to learners in CBT Interactive Multimedia Modules authors. From a relative superficial analysis, we are trying to show which types of dimensions should meet a minimum of expectations answers in this area. Our study corpus took concrete training projects:

- courses in vocational training,

- diffused by NICT such as Internet/Intranet and CD-ROMs supports, 
- taking advantages of CBT interactive multimedia modules.

From a methods point of view, we used the following feedback materials:

- formal evaluation of knowledge and know-how acquisition within the training environment,

- formal evaluation within the real job world usage,

- informal interviews at the end of the training and a year after.

All discovered critical points have been classified in different sets:

- a class of as issues having common causes in traditional training and Distance Learning approach using new technologies,

- a class of particular issues coming from the usage of new technologies and more specifically coming from the CBT Interactive Multimedia Modules usage.

\subsection{Distance Learning}

In order to build an efficient Distance Leaning model, the training resource has to respect the basic conditions acquired in traditional pedagogy experiences, at least:

1. a serious analysis of needs has to be done,

2. the design of the training system has to be based on observable pedagogical objectives,

3. a detailed evaluation of the prerequisites have to trigger the mode of teaching,

4. the formatting and the representation of the content, knowledge, know-how, has to match the learner capacity,

5. all the possible types of evaluation have to be engaged,

6. a serious dimension of coaching should be involved, such as handling the individual development path. 
All projects we used for our study had the following common additional pretentious objectives:

1. minimising the training costs - if possible the cost/hour/student had to be less than in a traditional approach few training resources for a lot of learners,

2. improving the acquisition efficiency - even if the learner had the opportunity to learn at his own progression,

3. space unit had to be broken - the majority of big companies are expecting to avoid loss of time and money for travels dedicated to employees' development - in addition enterprise management expect to find resources allowing "on job training solution",

4. time unit has also to be broken - the learners have different time better adapted for acquisition capacity - each trainee has a different acquisition rhythm - employers expect from the training suppliers solutions answering "on demand training" concept,

5. breaking the action unit is the third constraint to take into account - the teacher is no more the alone responsible of content formatting, distributing, evaluating, etc. - several specialists put in one or several forms the content a system, such as network, distribute it - other systems can force the evaluation, etc,

6. customisation of content structure meeting specific company needs - in vocational training the usage of a know-how is a key dimension insuring that an employee performs correctly.

\subsection{Study corpus}

Our analysis material counts about 50 courses. To give an idea of the type of training we give some representative examples. Respectively in presentation to designate each parameter:

Project Code / Type of organisation / Number of trained employees / Type of courses / Prerequisites / Estimated time spent for the training / Type of training resources / Additional comment find here summary data:

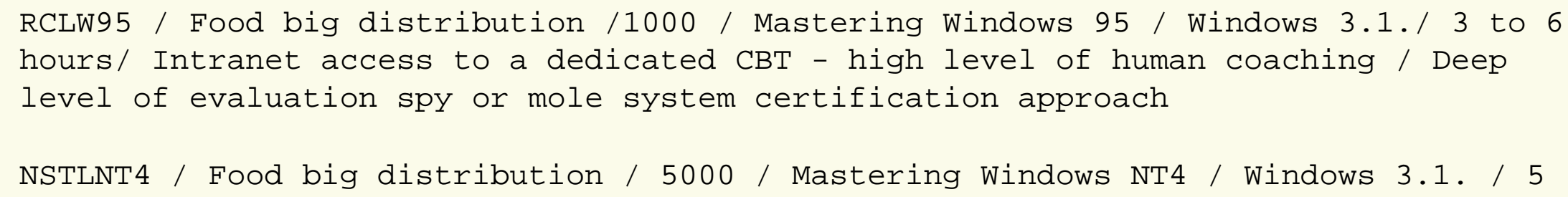


to 7 hours / Intranet access to a dedicated CBT - high level of training promotion / Low level of evaluation 1 year of deployment

NSTLOFFICE / Food big distribution / 5000 / Basic level of Word and Excel usage / Unknown / 5 to 12 hours / Standalone installed standard CBT package from the market / Low level of evaluation low level of coaching

AIDAVOCAT / Association of 17000 lawyers' offices / Currently about 3000 / Commercial management software / Unknown / Several days / About 1500 HTML pages dedicated and customised for this specific training / on job training approacho on demand approach

All the projects have been ordered by the enterprise or organisation management. The potential learners have never been involved in the training system and courses design. Nevertheless, each course has been tested, checked, adapted and calibrated on a sample chosen in learners' population. The level of prerequisite always was very heterogeneous.

Two projects were conducted by our customers with a deep thinking of how should be a training resource in Distance Learning approach. Two other projects have brought, in addition to a traditional evaluation, a strong certification system. We developed or used existing packages developed with an high level of simulation for almost all the projects dedicated to software usage. Major part of the projects were designed with a global acquisition evaluation system. Unfortunately, only few of them offered to the learners the opportunity to evaluate formally the training itself. Mainly, each CBT had "explanation", "practice", specific sub - know-how evaluation sequence. For each module specifically developed for a course, we put a very high effort in the segmentation of the knowledge and know-how.

Very few projects had the opportunity to find a parallel human organisation handling a minimum of coaching.

\subsection{Analysis map}

In order to keep the relevant issues related to the usage of new NICT, we organised our analyses creating the following 11 classes. We also assigned to each of this classes two properties: traditional pedagogy factors or Distance Learning and CBT specific factors. In a second step, we classified success and failure factors related to the:

1. training needs analysis [traditional pedagogy],

2. pedagogical objectives definitions [traditional pedagogy], 
3. design of the training system (who, what, how should be handled the training?) [traditional pedagogy],

4. didactic dimension (design, formatting, structure, presentation of the content) [specific to Distance Learning and CBT usage],

5. promotion of the training (how the training has been announced within the organisation) [traditional pedagogy],

6. prerequisite analysis [traditional pedagogy],

7. launching and diffusion of the content [specific to Distance Learning and CBT usage],

8. evaluation of the acquisition [traditional pedagogy],

9. training deployment [traditional pedagogy],

10. know-how evaluation in a real life situation [traditional pedagogy],

11. contextual dimension (integration of several courses in a courses management system, follow up of curricula individual development path follow up) [traditional pedagogy].

We used the learners' evaluation and feedback as main vector to track relevant failure factors. Due to the lack of formal training evaluation (training and not acquisition), we forced the learners to drive some introspection efforts to give additional relevant issues.

We early discovered that the major failing factors were falling in the "didactic dimension" class.

\subsection{Main analysis results}

We elaborate a set of hypothesises extracted from our experience in traditional training evaluation, tacking into account the known "cause to effect" relations.

We accepted as first premise that all learners were put in a self-taught (autodidact) situation. Consequently and based on this statement, we extracted mainly the following simple questions:

1. Did the learner reach the end of the training going through all expected steps including the specific sub - know- 
2. Did he obtain a better acquisition curve than in traditional learning?

3. Did he take advantage of the general offering brought by the Distance Learning concept such as learning during free time within a job situation?

We obviously were more interested by negative answers allowing us to ask some detailed questions. At this first level of analysis and in average we obtain at the first question:

- for courses built with a certification closing $100 \%$ of the population went trough all the training steps (as an example, in case of a training on Window 95, the management took the decision to implement a model similar to the driving licence: the information service installed the new Windows version on the employee's P.C. only when he was able to reach a minimum of score),

- in the training without certification, few training internal promotion, without opportunity given to employee to use immediately his know-how or without a strong management pressure, less then $50 \%$ met the end of the course.

For the second question we got results related to the taught discipline:

- in the case of software training, based on a set of know-how specific to manipulations and functions of a software, we obtain from an evaluation done a week after the training 2 times more of know-how kept compare to a traditional "in presence" approach. A detailed analysis showed that this result was obtain because each learner had the opportunity to adapt his learning rhythm,

- in the case of knowledge acquisition, we got same acquisition curves.

The answers to the third question were more difficult to analyse (our hypothesis corpus was not very well defined):

- in general the learners gave a very good feedback on the opportunity to avoid to follow, to wait, to be over-passed by a traditional group lecture,

- in some cases based on job to training the employees became learners during there free time, in the other cases they scheduled their learning, matching perfectly a traditional training situation, 
- the usage of the computer as CBT player platform, has never been an handicap,

- everybody recognised the network advantages to access CBTs.

In front of the enormous amount of factors and being not able to be exhaustive (our studies having $\underline{\text { no }}$ formal subvention but only personal and individual investments), we took the decision to focus our analysis related to the learner motivation and to try to understand why so many learners did not meet the end of the training module.

Fortunately, we had in our analysis materials a learners' population which had the "mandatory" opportunity to follow several courses based on a CBT approach. We obviously got a serious decrease of the motivation from a training to another: the gadget aspect of the first CBT practice decreased with the usage. We just put in a general wastebasket class this issue also valid for traditional training.

We had elaborated a second level of detailed questions on the negative previous answers. This set of questions was deliberated chosen avoiding to make reference to the CBT, such as:

- Does the training meet the objectives?

- Have you learnt what was need for your job?

- Does the company invest enough money for your training?

- Is the computer a good means to learn?

- Etc.

Even with questions trying to escape a feedback on the CBT, we were surprised how heavy was the learner focus on the CBT itself. This look like obvious, because in our different projects it was a way of structuring the content and the corresponding process of acquisition, it took the power of evaluation, it played the role of knowledge and know-how transmitter.

Therefore, we engage a third set of detailed questions directly addressing the CBT, such as:

- Was the CBT more adapted than a traditional lecture type of training? 
- Have you difficulties to navigate in the CBT?

- Went you often back in the explanation?

- Have you used all the functions brought by the CBT?

- Have you met some parts of the CBT which were unclear?

- For a specific sample of learners who jump some or all evaluation phases: why did you not went through the evaluation phases?

- Why did you not finish the CBT?

- Did you think that the CBT helped you to learn better?

- Which type of corrections or improvements can you bring to the used CBT?

- Etc.

Here are samples of negative answers which very often constitute a serious percentage of the feedback:

- It was boring!

- I did not understand a part of the CBT.

- Some explanations were not clear.

- I believe that I should play it again?

- I prefer training in presence.

- I was not able to practice a part of the module.

- I did not understand what was the objective. 
- The computer scientists make me upset!

- This type of training is addressed to children.

- Etc.

In front of a very serious amount of negative reactions, we started an analysis of about $100 \mathrm{CBT}$ of the market and 200 multimedia works selected in different genders such as: games and documentaries.

\section{STATE OF THE ART}

For this communication, we present only some examples of our studies which should impact the training of CBT authors or designers.

We were forced to define an analysis method. For each combined language, pictorial organisation, coding systems, sound articulations, music composition, interactive dimension, we try to use not only the analysis tools but also some manuals or treatises on the way to articulate linguistic elements or codes of each related discipline. As examples:

- for written language and from an analytical point of view, we try to apply the tools elaborated by the linguists, sign study specialists (De Saussure, Chomsky, Eco[31,32]), semantic specialists and rhetoric specialists (Jackobson[15]),

- for movie films and from an analytical point of view, we refers us to some treatise of movie film analysis (Mitry[4]) and from production stand point we reused the advises of staging, film production treatises,

- for music and from an analytical point of view, we have used musicology approach and from a creation reference point of view, we applied composer, harmony rules, etc.

We discovered that the majority of multimedia interactive works did not take advantage of the experience of each expression dimension. We additionally had some trouble to define "interactivity" and "navigation".

For this specific purpose we decided that interactivity can be define as: the freedom given by the authors to his readers to tell part of the story. We try also to define navigation as the means to extend space and time dimensions in a works.

Lets us to elaborate and illustrate a little on some relevant example we discovered in this part of our study. 


\subsection{CBT competencies}

We have not yet found a serious reference allowing us to answer to the question: had the CBT to be enough powerful to handle:

1. content presentation, explanation, demonstration, illustration, structuring,

2. simulation of real situations, know-how practice follow-up,

3. acquisition evaluation,

4. sometimes certifications capabilities.

Even if, from an analytical point of view this question looks like as CBT structure issue, it require a pedagogy specialists' orientation. If the answer is: CBT should take a maximum of training functions (which is by the way the pretentious objective of the majority of them) therefore, we have a typical example of CBT design failure. Lets accept to call the issue: the lack in "backtracking a learner error". Just to illustrate our statement we take a basic structure handling a know-how in CBT. In the following figure, we have extracted a frequent structure model: 


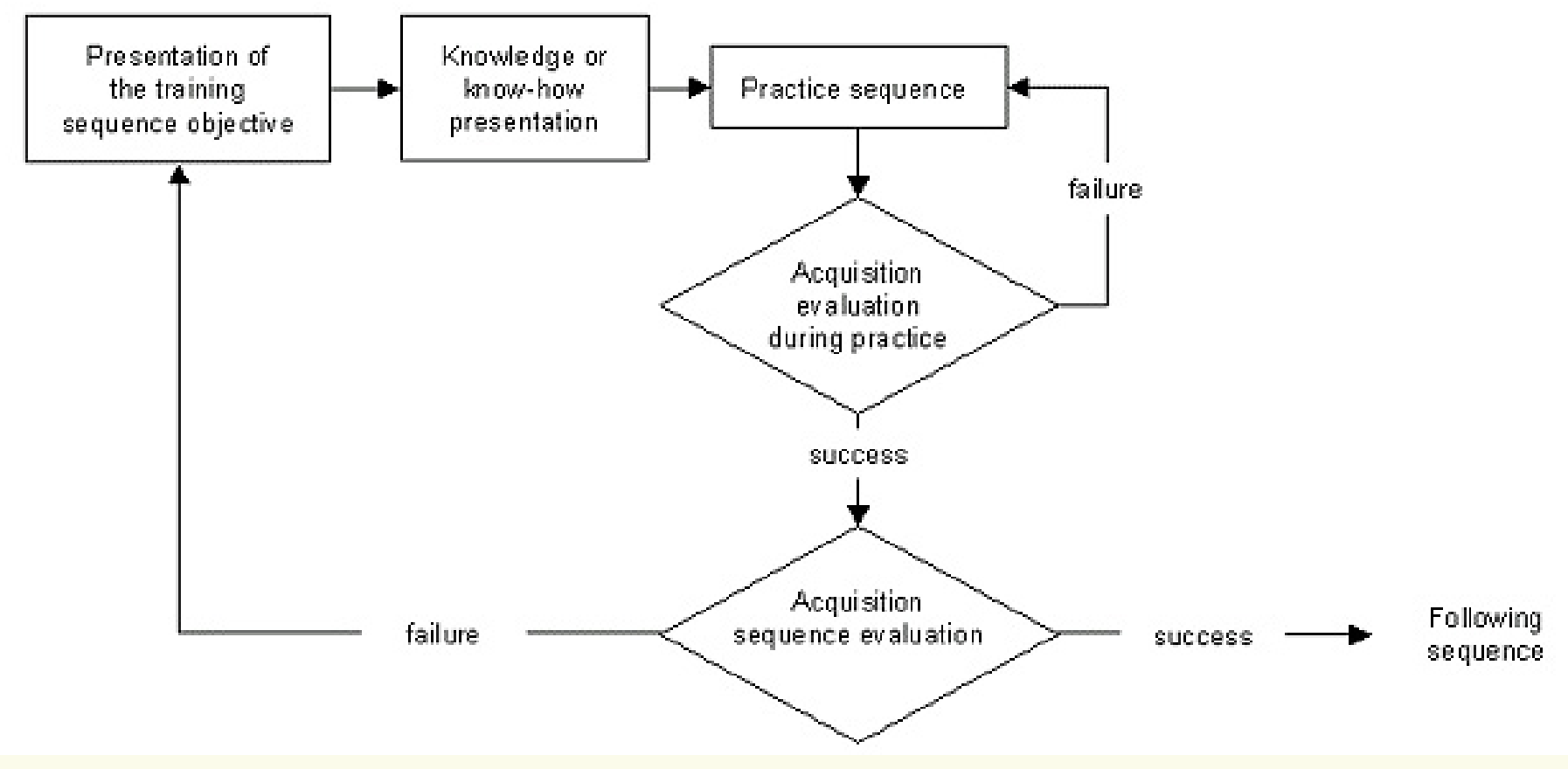

Figure 1. Two correction loops model

In our recording this structure already appeared as very elaborated model. It is working very well with a learner who did not failed or who failed very few times. In case of a learning candidate who failed several times, we can insure that he will lopping in the CBT. The structure model does not bring additional "information" in the loop.

We can expect some improvements in this structure. In a traditional teaching situation, the teacher will always leave his emphatic competence working. Consequently, applying a human relation model to this structure, avoiding that the learner start to loop without getting additional support for his acquisition, we will have: 


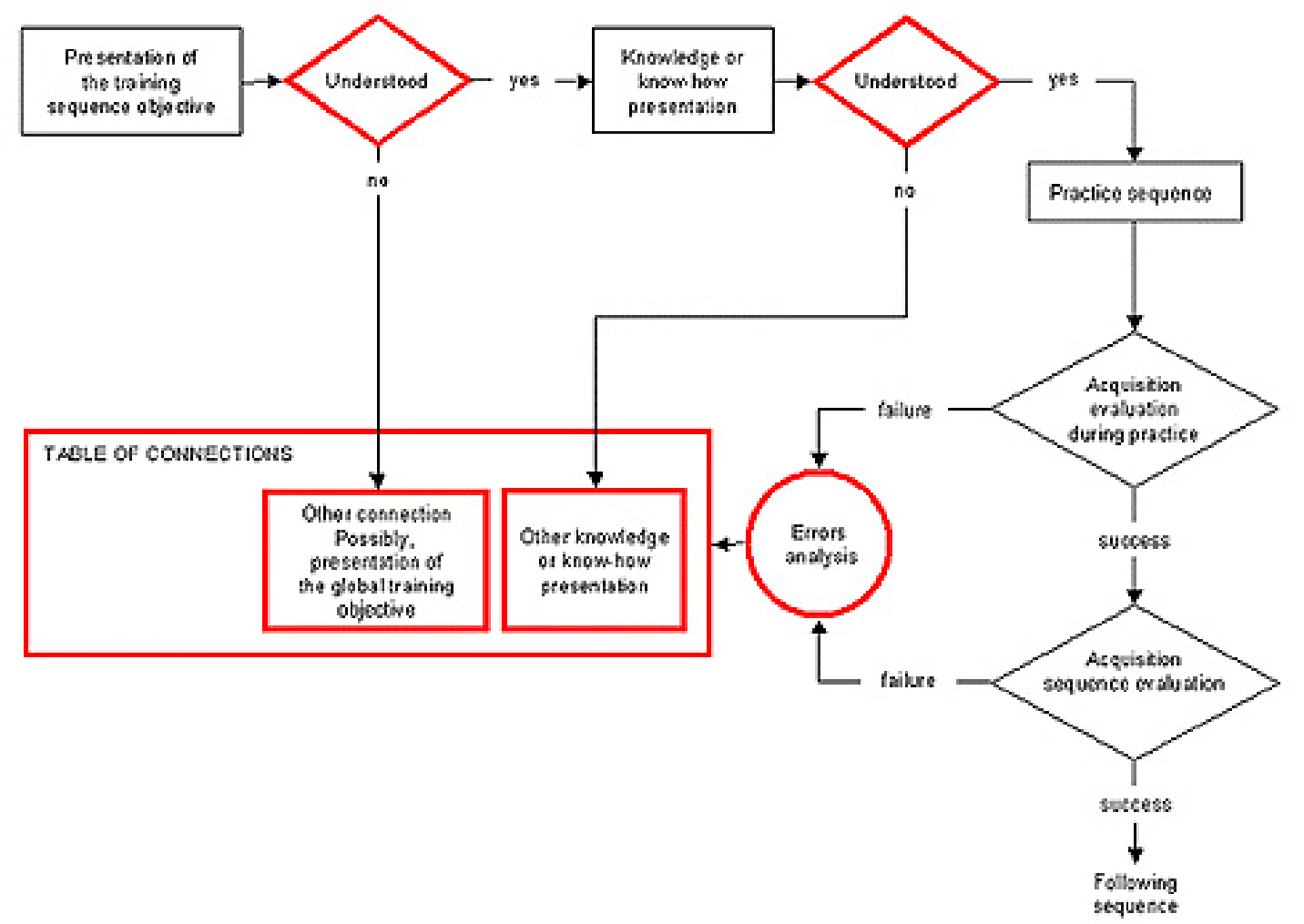

Figure 2. Emphatic adaptive backtracking model

This more complex structure model shows that a CBT which takes an evaluation competence should, at least, be built with:

- a maximum of check points giving to the learner a picture of emphatic dimension,

- an error processing system allowing to bring additional senses, information, points of view, content representations helping the learner to improve his acquisition. As an example, we never met in our studies the following type of structure, reworking the level of difficulties in an questions evaluation system: 


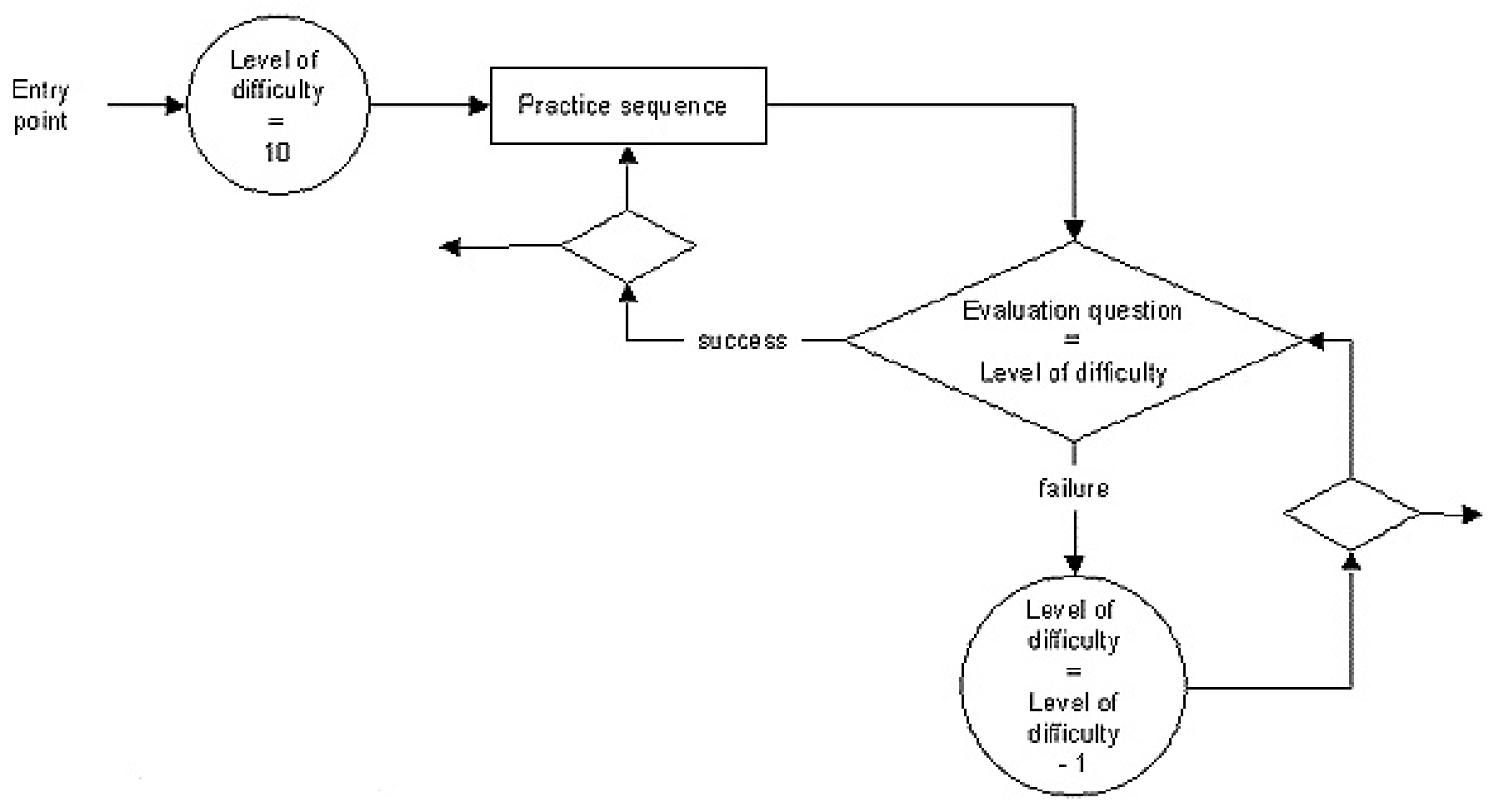

Figure 3. Adaptive evaluation system of questions, based on level of difficulties

- a maximum of differentiated content representation,

- a clear explanation of the learning sequence objective.

In conclusion, it seems that the competencies of pedagogy specialists are few involved in the design of existing CBTs. Very often the low level of money invested in the CBT production explains this lack.

\subsection{Improving the acquisition by interactivity usage}

To elaborate on the pedagogical dimension, we have also found very few efforts to give to the learner an opportunity to restructure the content. Any human being in a learning situation is restructuring, reformatting, reorganising a presented content to his mindset, according to his reference system, adapted to his experience, built to his education and culture. Fortunately, this means a lot of different content representations. Nevertheless, we know that a CBT cannot be designed 
with an exhaustive recording of representations. Therefore a CBT has to give to the learner a way of structuring the content according to his personal way of thinking and learning.

We just interrogate all the CBT corpus to discover that less then $10 \%$ had a printing function allowing the user to print part of the training to keep trace and to restructure the content matching his mindset structure. We have found less than $5 \%$ of CBT having annotation system allowing the learner to comment the content he was acquired.

Consequently, the CBT designers are not yet ready to use interactivity allowing the user to restructure the content. We do not make the CBT designers process. We are just sorry having to notice that the foundations and specificity of interactive multimedia potential are not yet exploited.

\subsection{Authoring tools impacts}

We very well know two main types of authoring tools:

1. Systems based on the book / page / card representation such as ToolBook, HyperCard, AuthorWare,

2. System driven by adaptive time units and casting representation such as Director.

All of them have common capacities such as:

- Playing several of different types of media,

- Integrating a lot of objects based on different support or formats,

- Offering drawing, animation, navigation facilities.

But, the way of representing a narration impacts a lot the designers. Lets take an example allowing us to illustrate this phenomena on the authors. Consider the following syllogism:

1. All frogs are green.

2. My grandmother is dressed with a greencoat.

3. Then, my grandmother is a frog! 
Take into account a primary set of elementary units of navigation. This element of navigation is used in a pages structure (screen structure) allowing the user to go to the previous page or the next page:

\section{Previous \\ page \\ Next \\ page}

Figure 4. Page per page elementary unit of navigation

For demonstration purpose, imagine that the authoring tool does not allow us to write more than one sentence per page. Consequently, to format our syllogism, we have a small book of three pages:

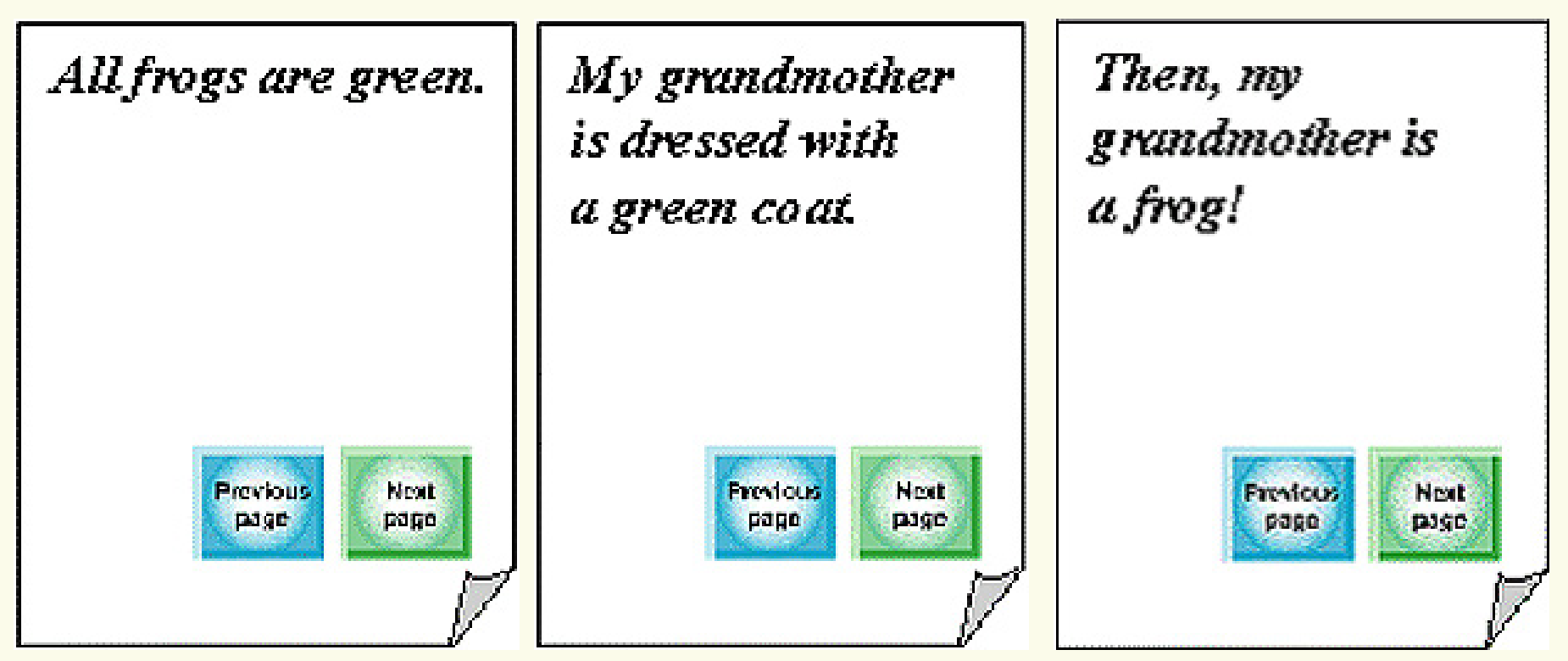

Figure 6. Example of formatting a piece of text 
Consider now that the learner is reading the syllogism. He reaches the last page, without understanding the content. For culture reasons and habits, he surely will turn back the pages to try to get the signification:

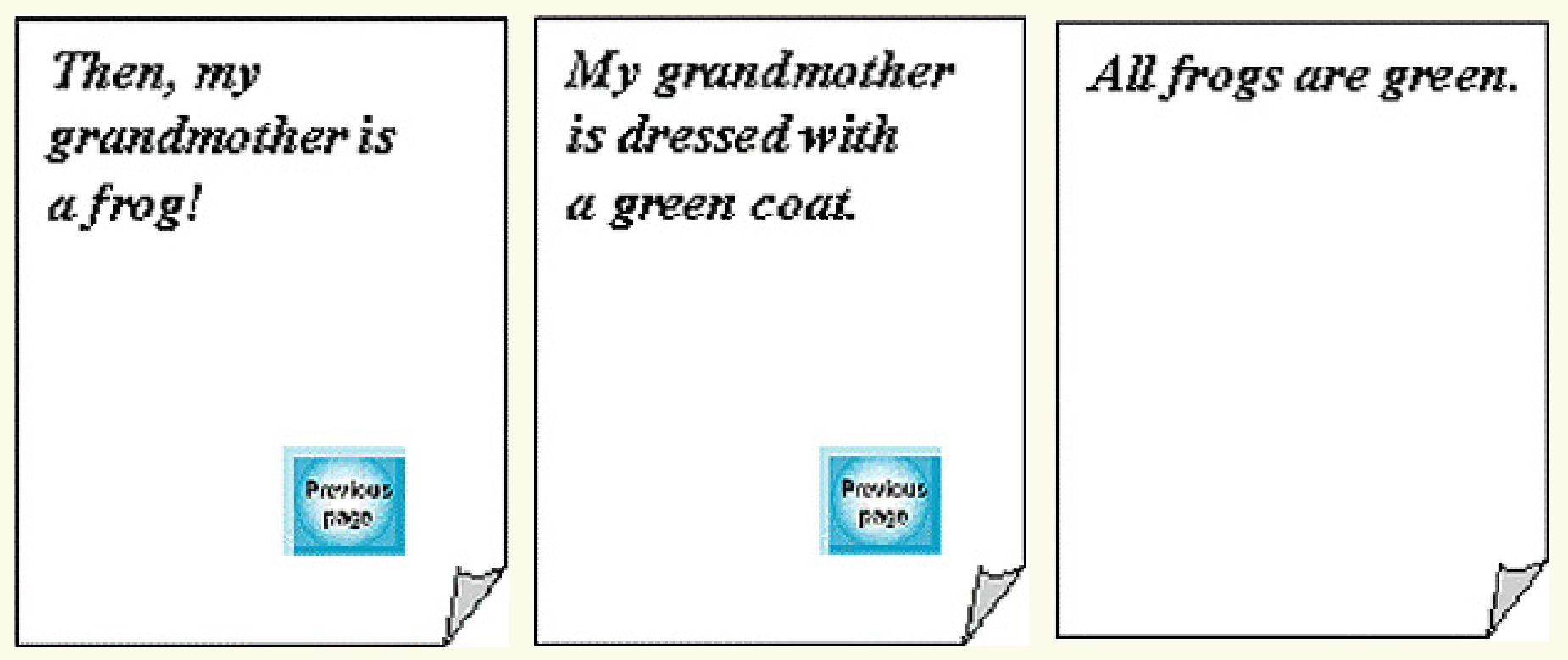

Figure 7. Reading the text in backward

From the syllogism conclusion, reading back the second premise does not give a sense to the complete statement. It bring sense complexity risking to disturb the reader. In fact the two premises constitute a semantic set:

Premises: 1a. All frogs are green.

1b. My grandmother is dressed with a green coat.

Conclusion: 2. Then, my grandmother is a frog!

Consequently, the means of navigating should be revisit (if we still have to keep a segmentation of 3 pages). One of possible way is to transform purely syntactical buttons (elementary unit of navigation: "previous and next pages") in bringing semantic such as a button which will be better adapted: 
Figure 8. Contribution of senses by the tools of navigation

Would you note that we do not propose a button such as "I have not understood". Indeed, we try to avoid possible negative strengthening in a learning situation. Consequently, we obtain for forward reading:
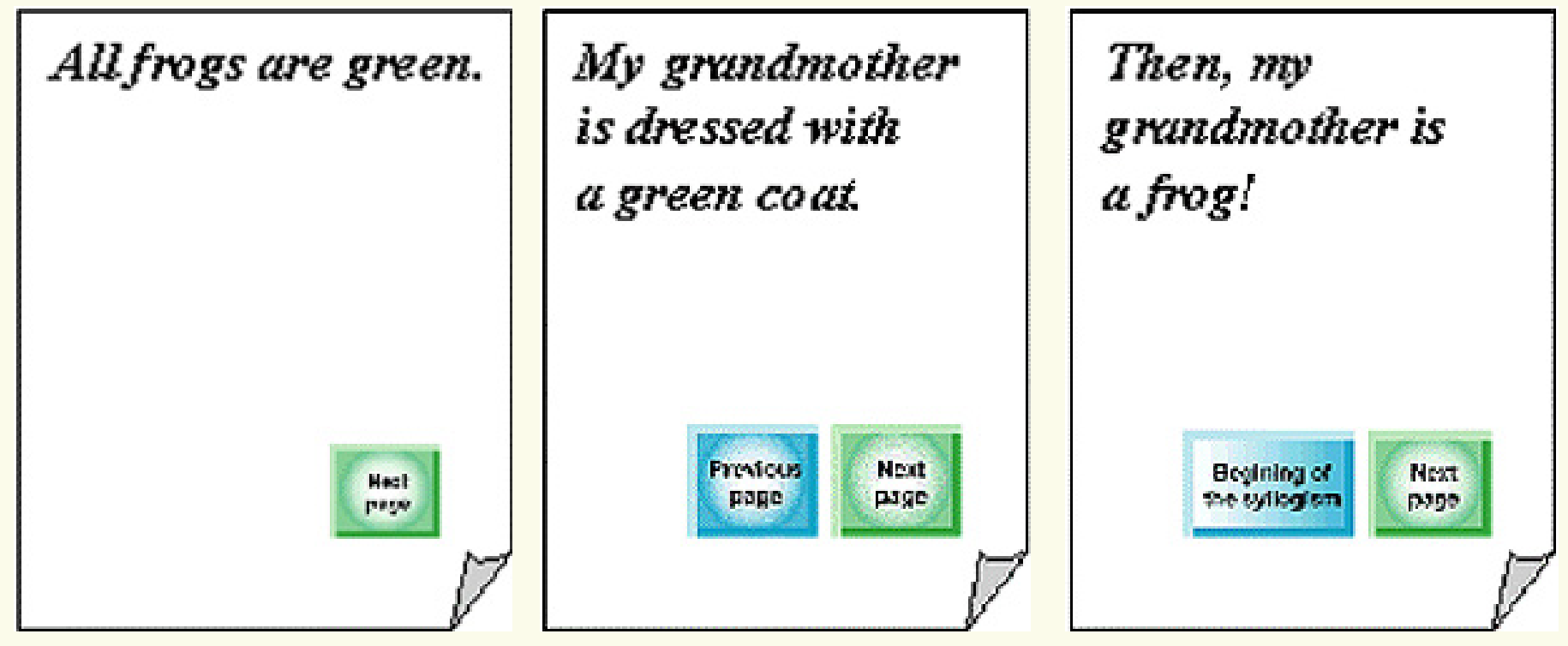

Figure 9. Same text structure, but new design of the tools of navigation

And for backward reading: 


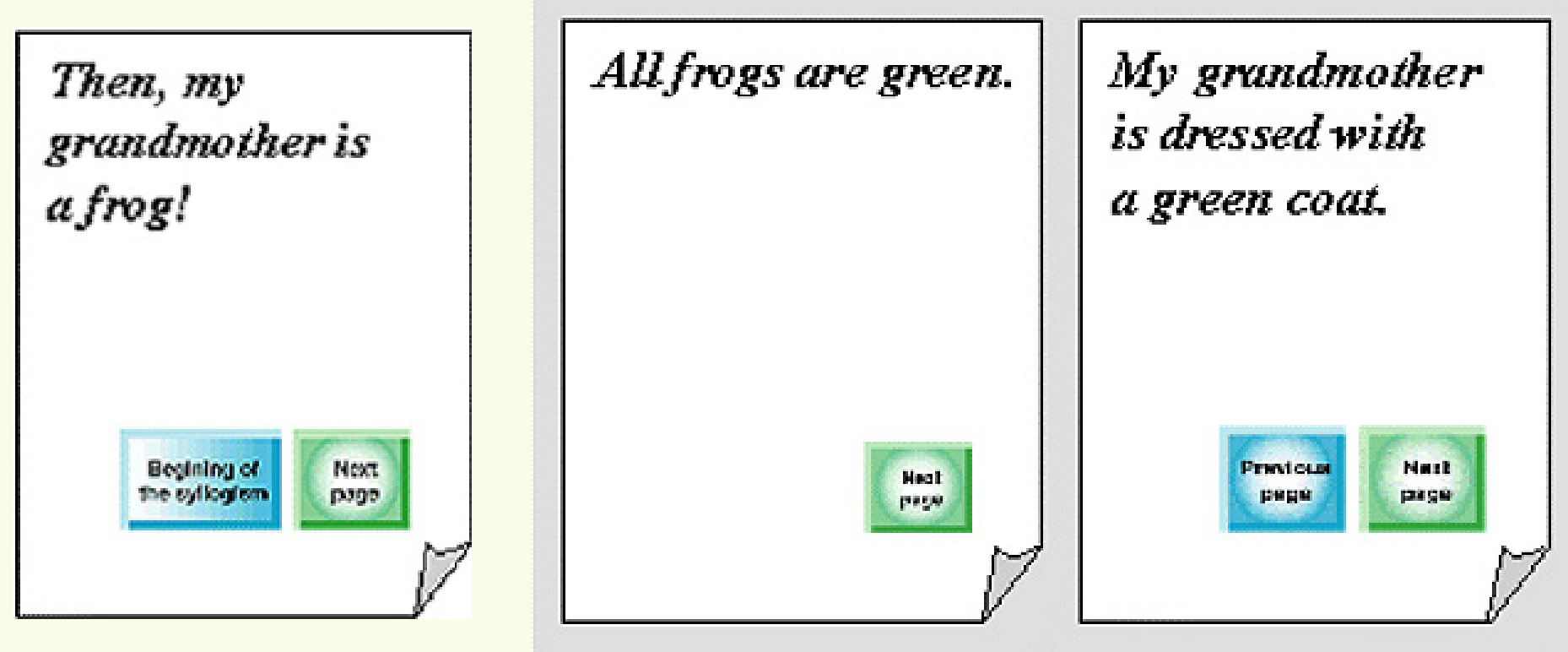

Figure 10. Part of the backwards reading becomes forward reading

In our analyses recording, we have met very few example subject to this level of understanding. Nevertheless, working this level of details will help the learner. We can supply more 100 examples related to the lack of thinking on the modularization of the content and the impacts brought by the type of authoring tools.

\subsection{Usage of video clips}

The usage of movie films or any type of clip is also very relevant, when integrated in a CBT. In analogy to previous illustration, we are just going to play a small video (one scene with a zoom camera move) in forward and backward direction: 


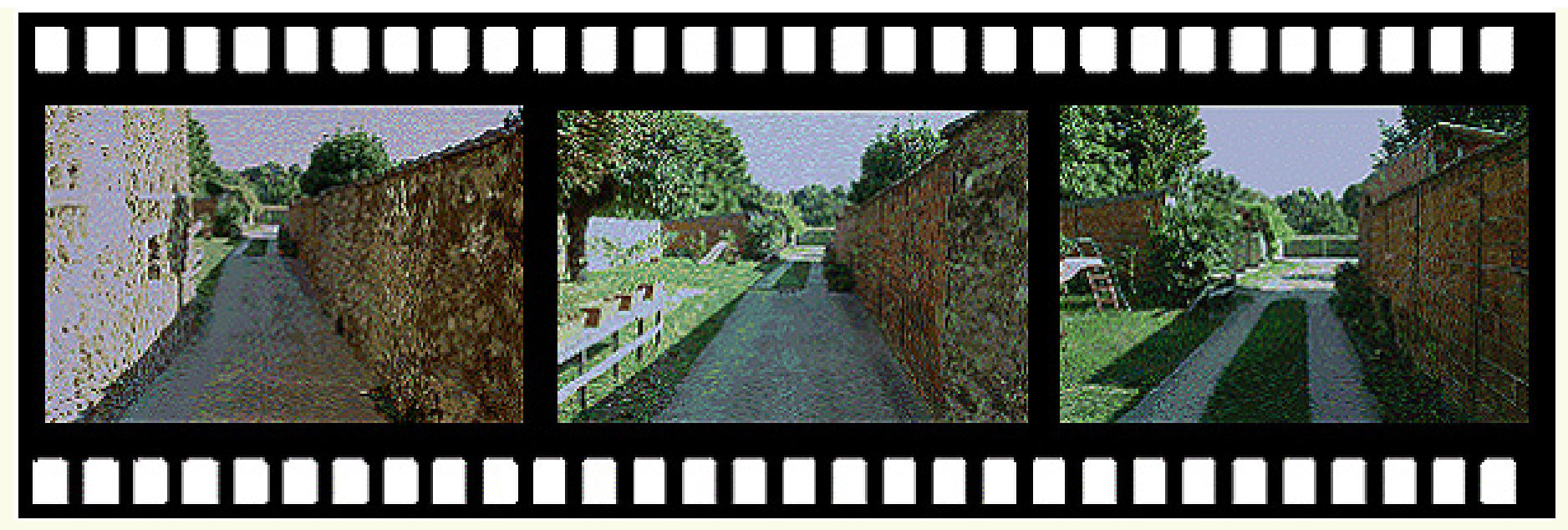

Figure 11. Camera zoom (forward)

We take an other primary set of elementary units of navigation such as videotape player commands allowing the user to go backward (not rewind) or forward a video:
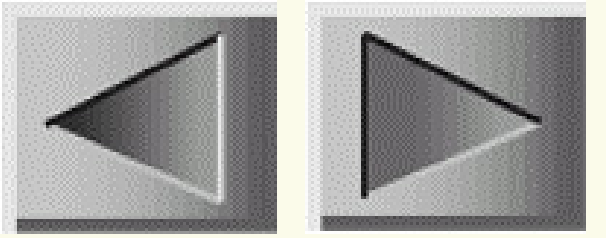

Figure 12. Elementary unit of navigation for linear video Backward / Forward commands

We have found a lot of video clips, which have probably not been designed for a multimedia module. Very often, when integrated in a multimedia work the designer offers a means to go backward in the clip. In our illustration we inverse the zoom: 

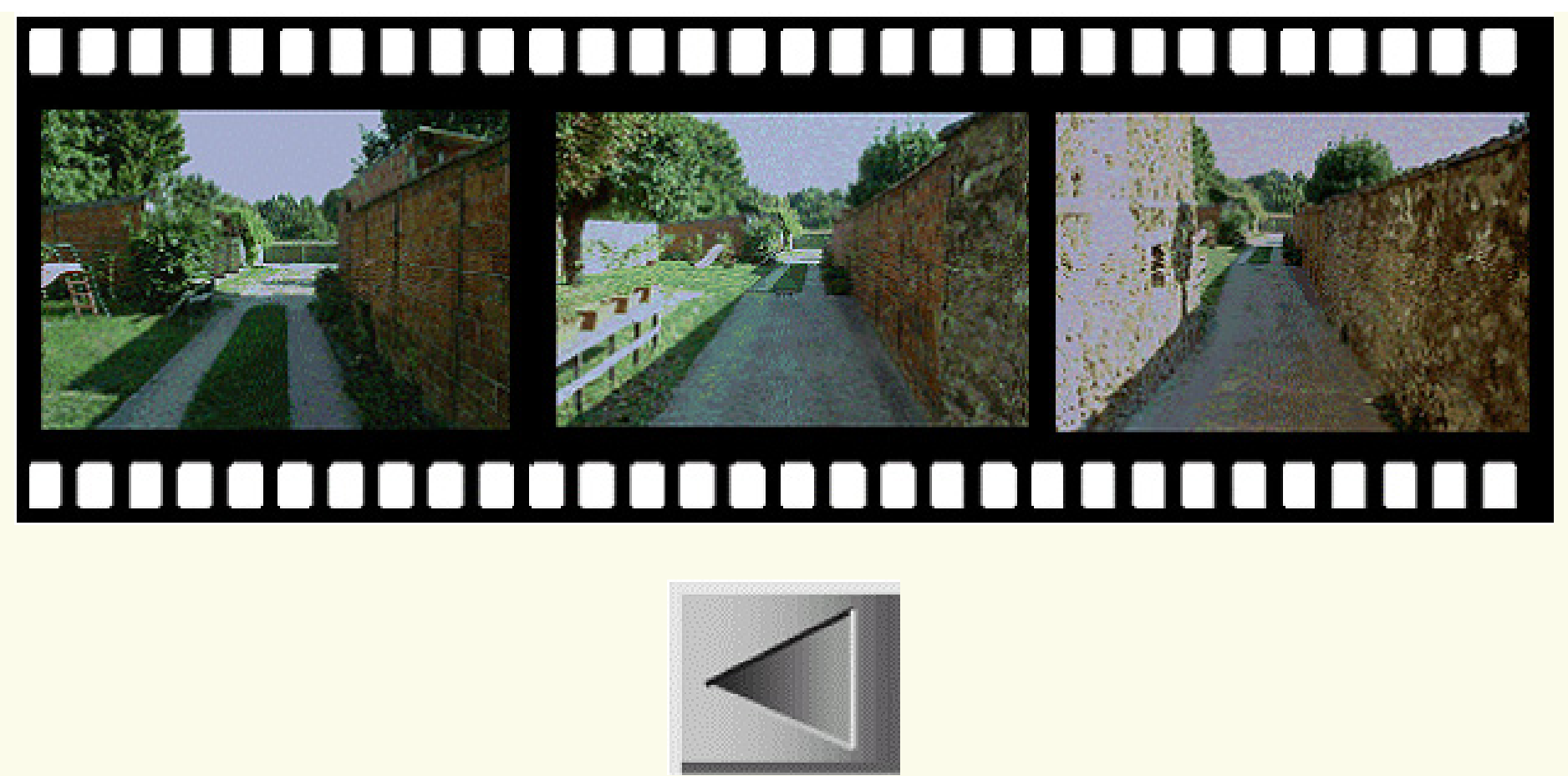

Figure 13. Inverted zoom

By the intrinsic linearity and semiotic genesis of movie films, the inversion of the movement does not bring a lot of information. Just imagine that the clip has been design to answer: "During your walk, please find the satellite antenna" and that we offer a navigation means allowing to change the camera angle:
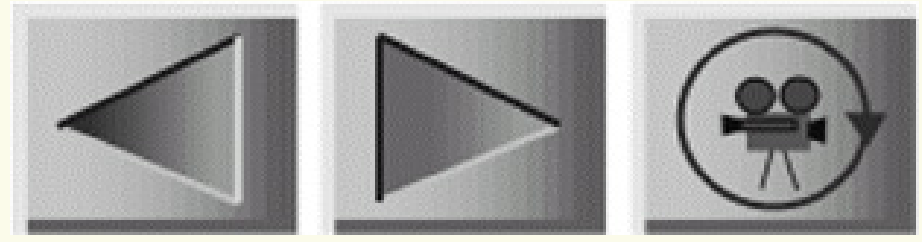

Figure 14. Complex navigation tool, space view interactivity combined with linearity movement

The angle change (in this example) will allow us find the expected object: 

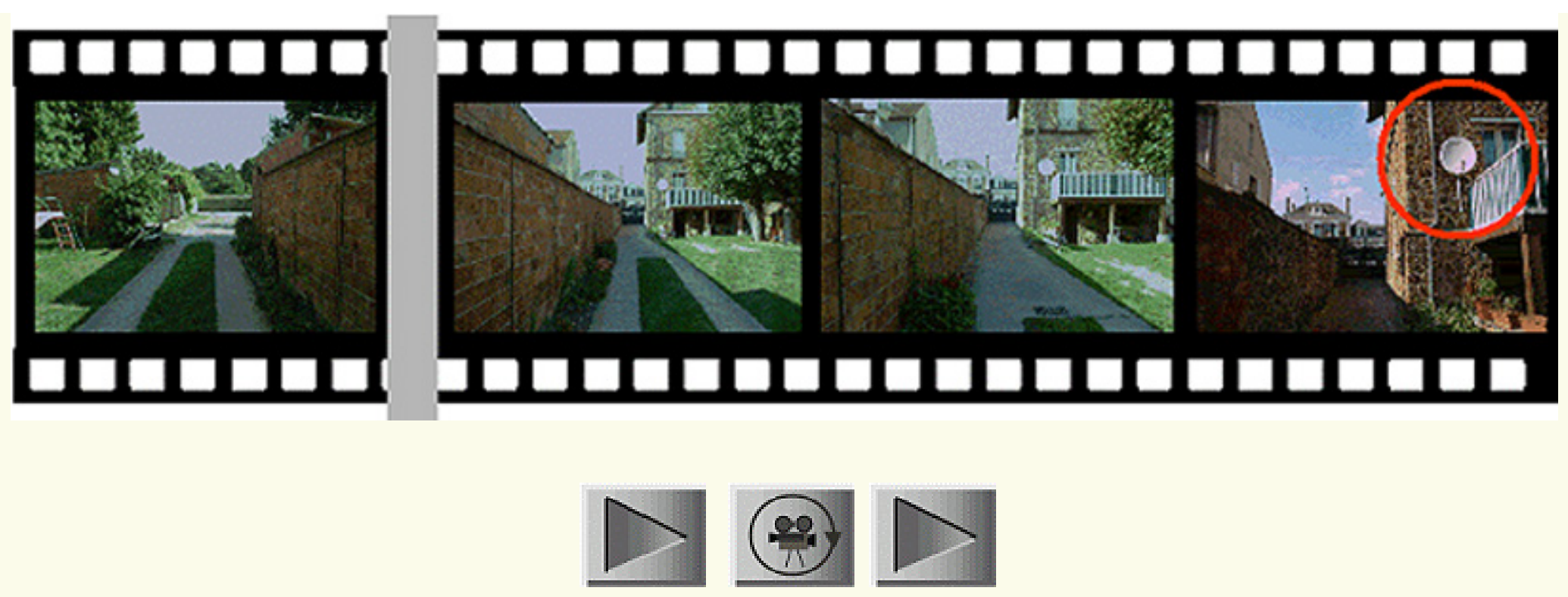

Figure 14. Contribution of the interactivity power to the sense by the view angle change

Nothing special to be stressed here. This a process very used in the games. We call it also "virtual reality". But this raises to a very interesting question. In case of games built on a set of sequence, do we find the same number of scenes in the forward than in the backward direction? In the bad and cheaper games the answer is yes. In the very elaborated games there no symmetry between the forward and backward progresses.

We very often find in games the following skeletal template: wait state - reader's action - answer of the multimedia module - wait state, etc: 

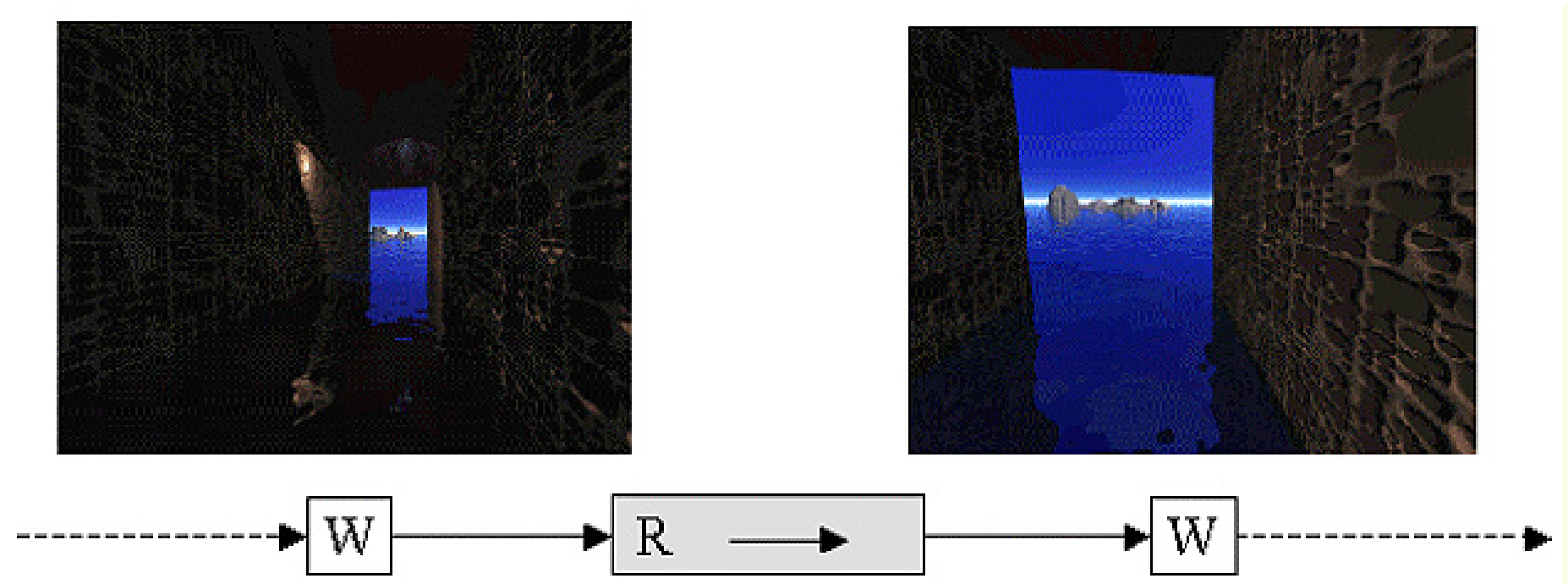

Figure 14. Sequence of wait and running states

The generic form can contain waiting states offering to the reader several alternative choices:

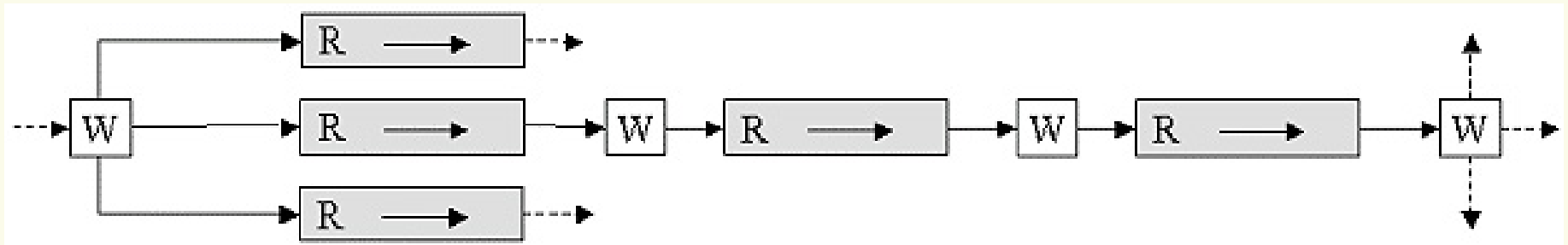

Figure 15. Some waiting states are offering several choices

Here is now a complete example of a structure which presents an asymmetric number of sequences: 

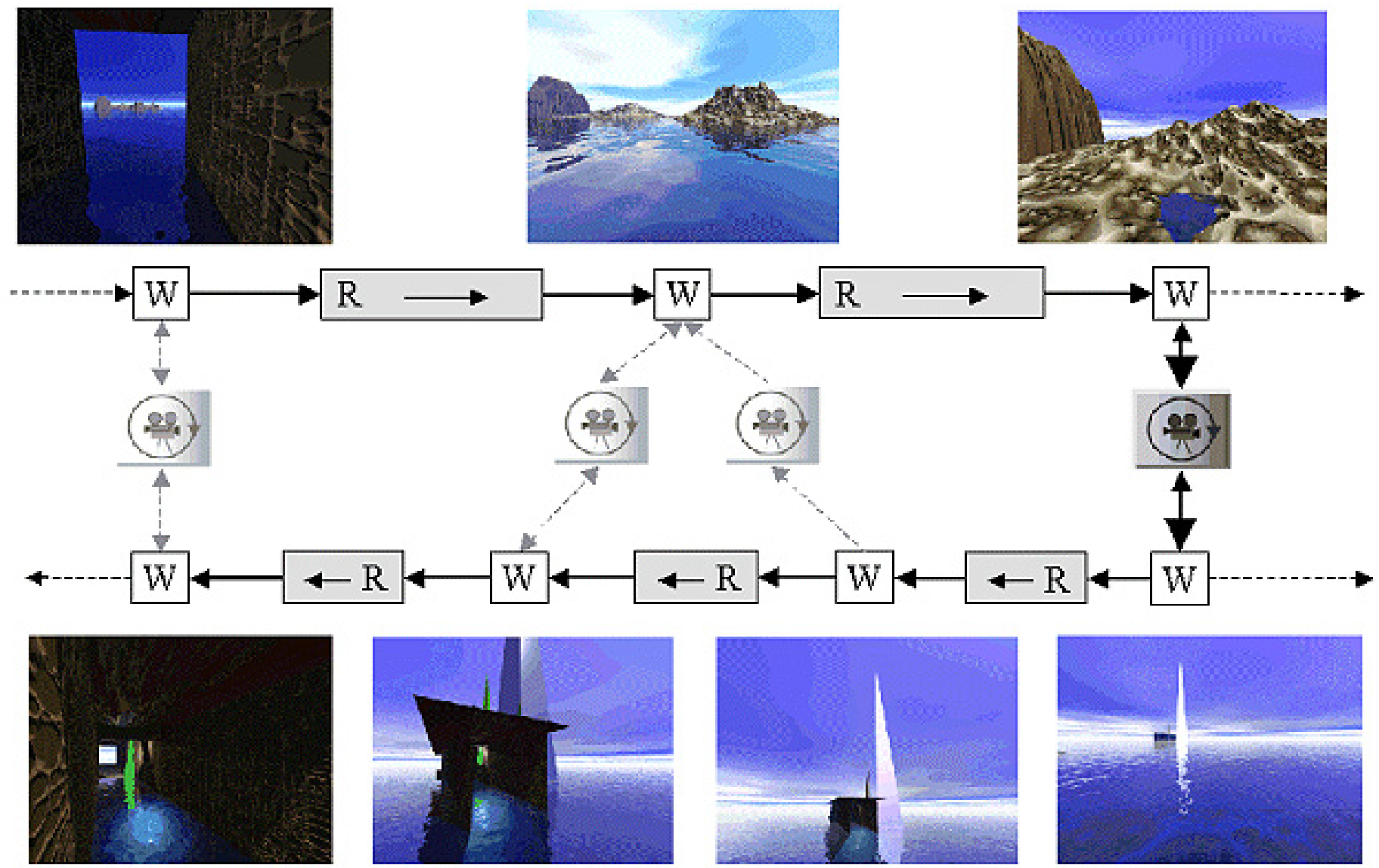

Figure 15. Some waiting states are offering several choices

We immediately foresee the interest being conscious and putting efforts in working these aspects in CBT. It insure a potential way backtracking errors and engaging possible other explanations in case of learner's miss-understanding.

If CBT should take advantage of interactive multimedia approach, it should bring additional feature on the traditional media (book, video, radio, etc). This type of structure are very difficult to be managed with traditional media. This means that authors have to manage very well the structure of they works.

\subsection{Graph structure}

Formally, any interactive multimedia works is design around the navigation opportunities. This can be represented by a 
graph (in the mathematics sense). Each waiting state, where the user have to take a decision and make an action is represented by a node. The arrow between the nodes is used to show the transition to a new state:

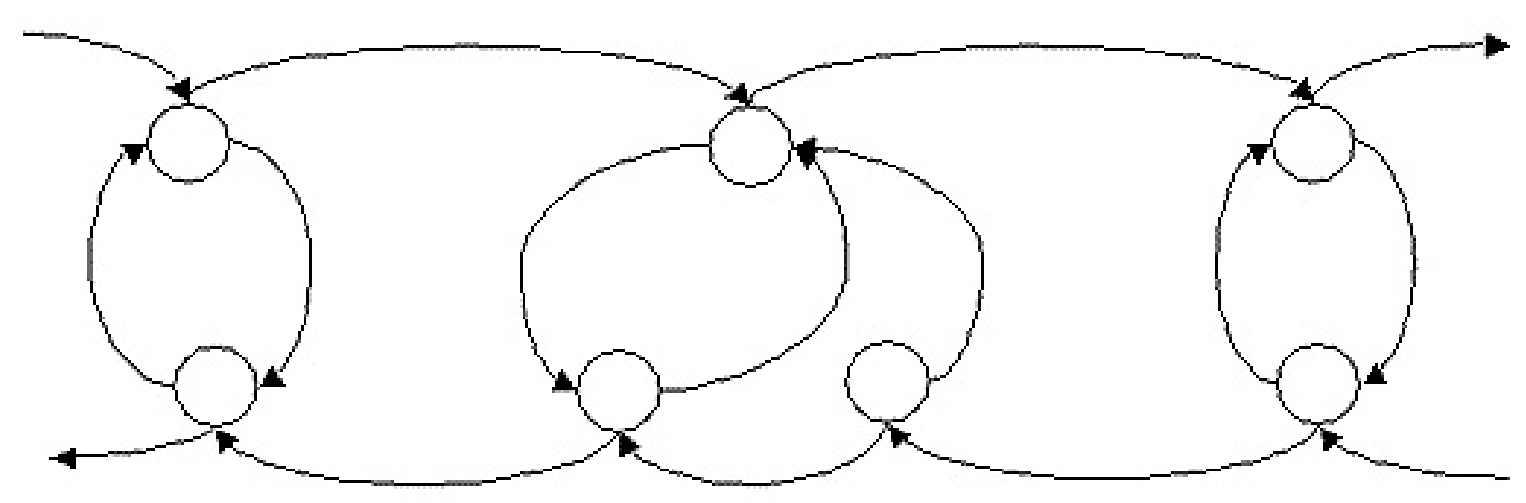

Figure 16. Graph structure of the Figure 15

There are different generic structures of graph defined by the way of visiting each node such as oriented graphs, hierarchical structure, etc. In our analysis, we have found about 30 types of possible improvements to be brought to CBTs. In couple of works, we even have found graphs where some node can never be visited:

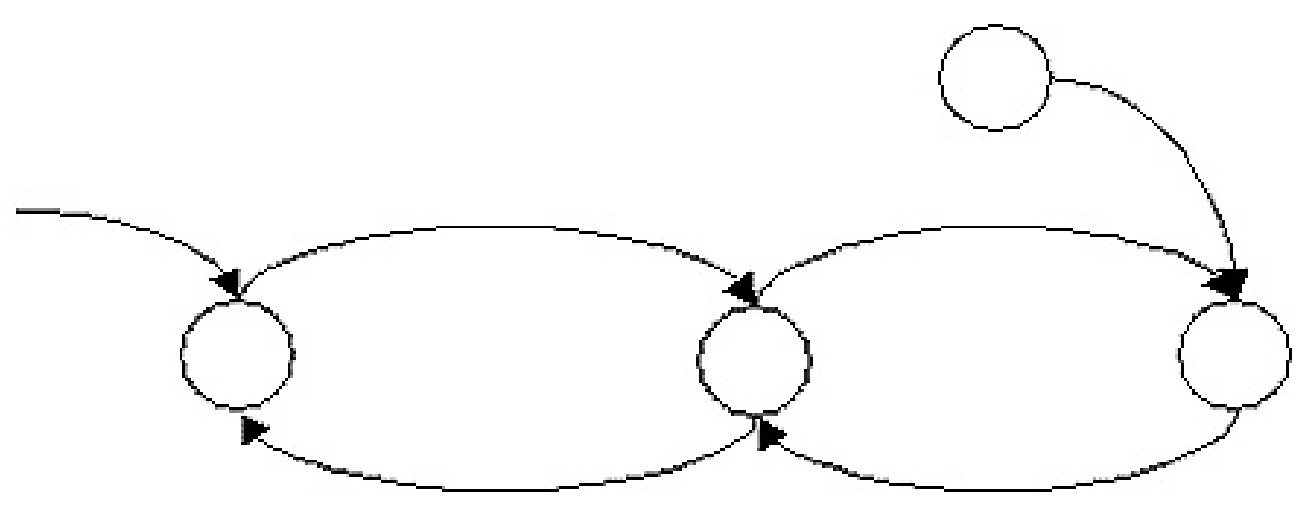

Figure 17. Lost node

A global structure of graph can converge or diverge: 


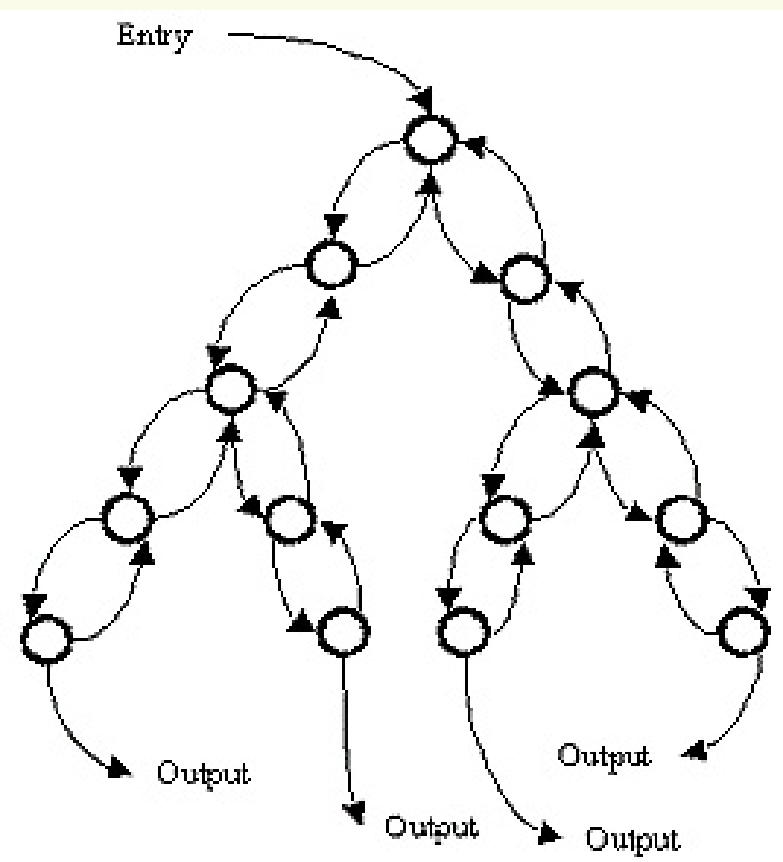

A. Divergent structure

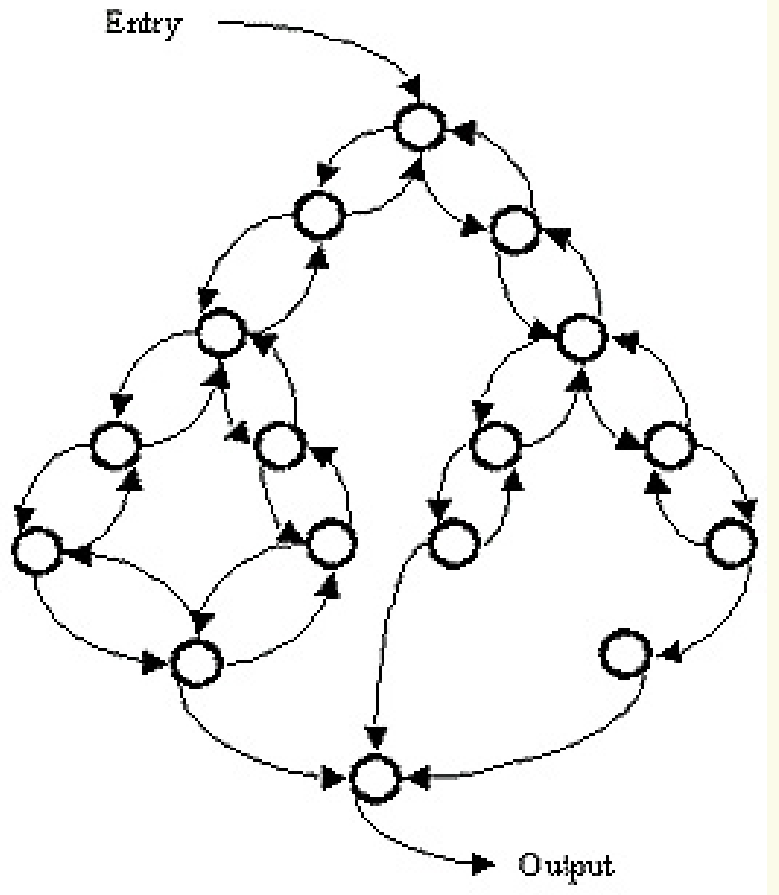

B. Convergent structure

Figure 17. Examples of global graph structure

The divergent form works well in case of encyclopaedia or documentary gender. But, knowing that in a training situation the content synthesis, positive strengthening, concepts consolidation are successful keys, we have been surprised to find a lot of CBTs which were designed on divergent structure.

\subsection{Means of expression combination}

We also notice some difficulties coming from the combination of different expression means. In standalone language the rhetoric functions are already something difficult to master. When combining different languages and code systems, it obviously becomes complex. We count more than 20 basic rhetoric functions in the audiovisuals (pleonasm, illustrative, explicative, emphatic, etc). In our recording, we have found an enormous amount of questions which looks like as a miss-usage. The movie film makers know that if they will establish a smooth link between two scenes, they have to take 
into account where the spectator has focused his look on the previous screen.

In the following screen there are couple of implicit navigation means that the player has to find. As well defined in our occidental culture, we finished to read a "written" page at the bottom right. In our case the implicit button representing a door on the ocean:

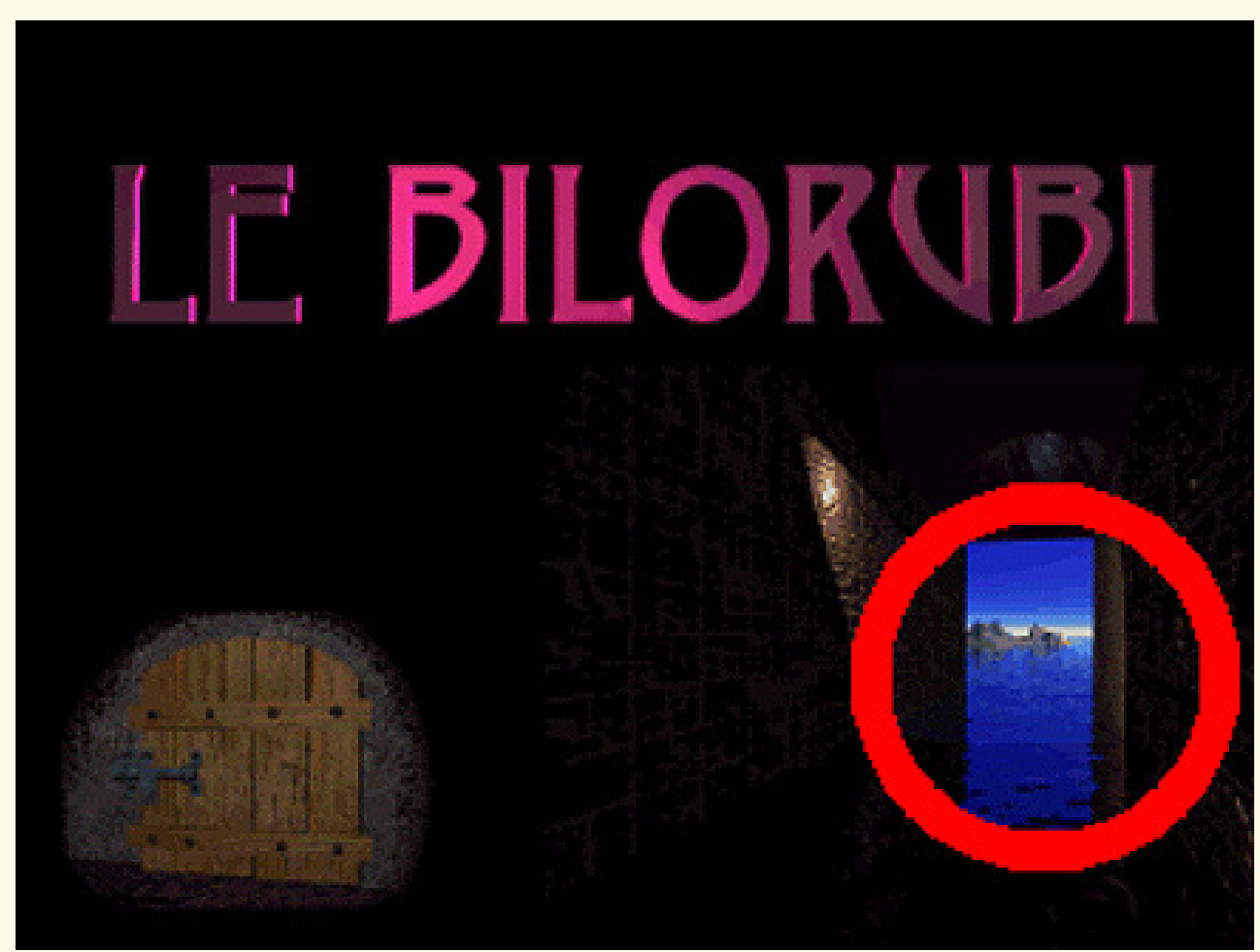

Figure 18. When clicking on the implicit button "door on the ocean" the user is focusing his look at the button right of the screen

Now take the following scene obtained by the user after the click action. His look is focused on the centre of the screen: 

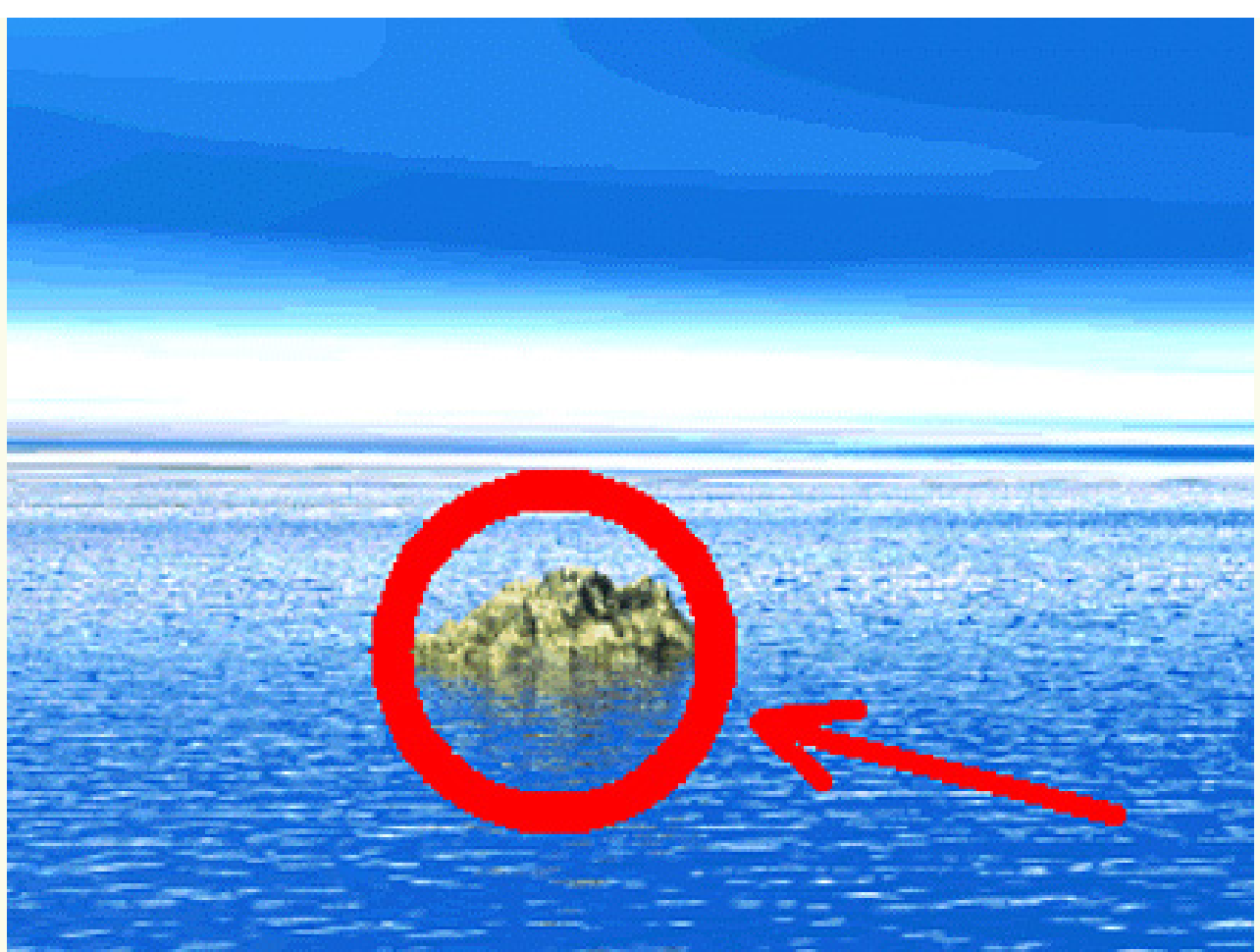

Figure 19. Transition ellipse which can feel as a bad jump

We also counted miss-usage of the rest of rules known by the movie film makers in staging competencies such as: respect lack of the $180^{\circ}$ rule (a sure way to lose his reader or spectator), field on field transition, bad framing for small screen, etc.

Even if it looks like as details or sometimes naive, this sample of examples are participating to a part to the reasons which can help to decrease learners' motivation.

\section{EXPLANATION TENTATIVE}

Several questions can be addressed to understand where this negative picture come from.

- Why globally do we reach these delicate observations?

- Who currently is designing interactive multimedia CBTs? 
- Which is the technical impacts?

- Today, what is the training of multimedia designers? What are their backgrounds?

\subsection{Global observation}

There is no secret! The different CBT suppliers does not find the right investments to reach the expected level of quality. Even if a lot of projects are on going, our experience shows that customers and consumers are not yet ready to pay the same price for a traditional training and a new way of thinking learning.

To often, only the customer is considered in the analysis of needs. We make here a strong difference between the customer: management of enterprise or bureaucrat of institutions and the consumers: the learners. Additionally, the expected learner's centric approach is forgotten in favour of a trainee's focus approach.

As television and broadcasting experience, any new media business start by fulfil the quantitative expectations. The quality becomes a differentiation factor, only when the competition start on the market. Today, we still are in the first phase.

More investment are currently done in the diffusion channels (telecommunication providers), in the business form, in the business of games than in the content development.

\subsection{The today design approach}

In CBT gender, we firstly were surprised by the regular absence of pedagogy and didactic specialists. Even if treated discipline is subject to a specialist and, may be, with a teacher experience, the privileged trades, professionals, workers to build a CBT development team are mainly taken in graphic arts and in computer sciences.

To build an ideal team dedicated to a CBT development needs a lot of existing competencies, at least: pedagogy, didactic, discipline specialists, graphic specialists, photography competencies, movie film makers, sound specialists, musicians, authors of texts, project management. Due to the novelty, some new competencies or specialisation's have to be developed: multimedia integration, multimedia operators, multimedia authors, multimedia producers, etc.

\subsection{Technical impacts}

It is very difficult to convince a good creator from traditional media accepting to start in multimedia domains. New technologies are mainly mastered by the computer scientists who are not always ready to communicate in a team. The 
current technical constraints in terms of quality, space for recording, speed of the communication channels make upset professionals of traditional media.

The competitions engaged by Internet against other support still bring today very low level description language (HTML). To overpass this lack of knowledge representation needs again computer specialists (ActiveX, Java Code, Plugins, etc). The authoring tools are not yet adapted to allow teachers to start to create content without having high computer science abilities.

CPU manufacturers' and software publishers' competition does not allow the market to stabilised the technology used in CBT development.

\subsection{Current training of multimedia designers}

A lot of courses are given for multimedia competencies acquisition. It is very often punctual training or post-grade specialisation. When analysing the different curricula, we have noticed that the addressed subject are mainly oriented to technical issues. Very few training are reserved for future authors.

\section{TRAINING OF CBT AUTHORS}

Since years 80's we are talking about NICT usage for developing multimedia works or CBTs. Nevertheless, 15 years after, few efforts have been devolved to the training of authors. Here again some questions should be subject to answers:

- What is the scope and competencies of CBT authors in an ideal team? Where does the author work start and finish?

- What have we already to help CBT designers allowing them to improve their works?

What is the scope of an author's job? Where start the work of a CBT author? The answer can only be approximated, but we think that the following steps of pre-producing phase should be covered:

1. In collaboration with a pedagogy specialist, working the idea with the customer and (if possible) with some consumers (representative of the future learners),

2. Elaborate a linear story, narration, and linear structure,

3. Reorganising the story in a first segmentation as a movie film scenario, 
4. In collaboration with a computer scientist, defining the navigation and interactivity,

5. Build the global graph of the navigation,

6. In collaboration with specialised designers (graphic arts, movie film makers, sign and coding aspect specialist, ergonomic aspect specialist), defining the aesthetic, the different rhetoric functions, the user interface look, etc,

7. Compiling all precedent documents as a story board book,

8. Helping the producer to create the first level of budget,

9. Participating in the decision of fusibility within a team made of the producer (investment source), the technical specialist (computer scientists), diffusion responsible (distribution channels),

10. Participating to the elaboration of the instruction lists dedicated to each member involved in the production,

11. Participation to the project plan development,

12. Participation to key project millstones during the production and post-production.

According to this first sample, it appears that several sub-tasks looks like as more oriented to something we call design.

In our CBT analysis, we have noticed that very often the way of iconography coding is changing without explanation. The aesthetic is not kept form the beginning to the end of the work. In a low level work, it is possible to count the number of info-graphic workers being involved. Too often nobody is really care of the homogeneity of the work.

Therefore, before tailoring the multimedia work, we are prone to think that the authors should be able to cover the designing tasks and responsibilities to.

This obviously drives us into a very pretentious training objective. Is it possible to meet such goal, when knowing that we have to start by the training of trainers? Surely yes, if the objective does not expect to make good creators. The first step should address a high level of competencies and not performances. Like we try to teach young children in their mother tongue: we are not expecting that all of them could become famous poets.

\section{TEMPORARY CONCLUSION}


Firstly, a big effort has to be done helping to minimised the computer scientist power in a CBT development team. By definition the technical constraints should become a way of expressing an idea. The movie film makers were able to regress to the television media and sometimes being able to generate something which look like to a chief of work. The gadget aspects brought by the computer technology has to be proscribed.

Secondly, in front of the complexity and according to our experience in teaching audiovisuals specialists, who had as prerequisite scenario elaboration competencies, we reached the conclusion that this training cannot be done on job training. The author's trainee should totally dedicate his time for this purpose.

Thirdly, we are not yet able to answer to the question: is it better to train people having no similar knowledge or know-how in one of the multimedia domain or do we have to expect background in one of the closed area to multimedia competencies?

At Internet age, it is surprising how heavy is the gadgets and technicians' power. In comparison, it is a injury to observe how low are the reasons to tell a story (with sense). Helping people for their knowledge and know-how development starts with the ability to tell correctly a story.

\section{REFERENCES}

\section{Audiovisuals, television, movie films:}

[1] CLOUTIER, Jean, La communication audio-scripto-visuelle à l'heure des self-média ou l'ère d'Emerec, Les Presses de l’Université de Montréal, 241 p., Montréal, 1973. \{pédagogie, sociologie, techniques \}

[2] BERGER, René, La télé-fission, alerte à la télévision, Casterman Col. Synthèse Contemporaines, 210 p., 1976.

[3] BÜREN von, W., Brüderli S., Fisler K., etc., Le monde télévisé, la politique d'information télévisée en système capitaliste, une analyse du téléjournal suisse, Editions Cedips 200 p., Lausanne, 1976. \{politique, sociologie, média\}

[4] MITRY, Jean, Esthétique et psychologie du cinéma, 2 volumes, Editions Universitaires, 426 p. et 466 p., Paris, 1963.

\section{Culture, arts, technics, technology, knowledge:}

[5] ANDRIEUX, Michel, (préface), Gruas Pierre-E., (Introduction), (ouvrage collectif), Enfance et cultures, problématiques de la différence et pratiques de l'interculturel, rapport ANPASE, Editions Privat, 328 p., Toulouse, 1986. 
[6] CHION, Michel, Musiques - médias et technologies, Flammarion, Col. Dominos, 127 p., 1994. \{nouvelles technologies\}

[7] DEMORGON, Jacques, L'exploration interculturelle - Pour une pédagogie internationale, Armand Colin Editeur, Col. Biblio. Européenne des Sciences de l'Education, 325 p., Paris, 1089.

\section{Economy:}

[8] GUITTON, Henri, Economie politique, Introduction Générale, Analyse micro économique, Analyse macro économique, Onzième Edition, Précis Dalloz, Dalloz, 701 p., 1976.

\section{Management:}

[9] KOONTZ, H. et O’DONNELL, C., Management - principes et méthodes de gestion, McGraw-Hill, Éditeurs, La Collection Administration, traduit et adapté par Gilles Ducharme, 618 p., Québec, 1980.

\section{Picture, icone, sign, symbols:}

[10] GERVEREAU, Laurent, Voir, comprendre, analyser les images, Editions La Découverte, Col. Guides Repères, 192 p., Paris, 1994.

[11] Ouvrage collectif, Réalités de l’Image, Image de la réalité, No 1, Mars 1996, Editions L’Harmattan, 157 p., 1996.

[12] TISSERON, Serge, Psychanalyse de l'Image. De l'imago aux images virtuelles, Dunod, Col. psychismes, 212 p., Paris, 1995.

\section{Linguistic:}

[13] DUBOIS, J., LAGANE, R., La nouvelle grammaire du français, Larousse, Paris, 1973.

[14] GREIMAS, A.J., Sémantique structurale, Langue et langages, Larousse, Paris 1977.

[15] JAKOBSON, Roman, Essais de linguistique générale, traduit de l'anglais et préfacé par Nicols Ruwet, Edition de Minuit, 255 p., 1963.

[16] LE GUERN, M., Sémantique de la métaphore et de la métonymie, Langue et langages, Larousse, Paris 1972. 


\section{Market:}

[17] ASSAEL, Henry, Marketing Principle \& Strategy, Second Edition, The Dryden Press, Hartcourt Bracce Jovanovich, Fort Worth, 771 p. + annexes, 1990.

[18] BRETON, Thierry, Les Téléservices en France. Quels Marchés pour les autoroutes de l'information?, (Rapport officiel), La documentation française, 616 p., Paris, 1994.

[19] LIVINGSTONE, John L., MBA Finances - Synthèse des meilleurs cours des grandes Business Schools américaines, Maxima - Laurent du Mesnil Editeur, traduit de l'américain par James Rauch, 413 p., Boulogne, 1993.

[20] PAQUEL, Norbert, L'édition et les supports multimédia - Marchés et perspective, A jour, éditeur, 75001 Paris, 1993.

\section{Media, new media:}

[21] CHARON, Jean-Marie, (sous la direction de ), L'état des médias, Editions La Découverte, Col. Médiaspouvoirs / CFPJ, 461 p., Paris, 1991.

\section{New Information \& Communication Technologies}

[22] COMPAINE, Benjamin M., (edited by), Understanding New Media, Ballinger Publishing Company, ISDN 0-88410977-1, 378 p., Cambridge - Massachusetts (USA), 1984.

[23] FISHER, Scott, Multimedia Authoring, Building And Developping Documents, AP Professional, 286 p., Massachusetts, 1994.

[24] IUPPA, Nicholas V., Designing interactive digital media, Focal Press, 208 p., ISBN 0-240-80287-X, U.S.A., 1998.

[25] JACOBIAK, François, L'information scientifique et technique, Presses Universitaires de France, Col. Que sais-je?, 123 p., Paris, 1995. \{gestion\}

[26] LOPUCK, Lisa, Designing multimedia - A visual guide to multimedia and online graphic design, Peachpit Press, 148 p., ISBN 0-201-88398-8, Berkeley., 1996.

[27] TOUCHARD, Jean-Batiste, Multimédia Interactif, Edition et Production, Microsoft Press (Diffusion Eyrolles), 187 


\section{p., 1993.}

[28] VAUGHAN, Tay, Multimedia - Making It Work, second edition, Osborne Mcgraw-hill 560 p., Berkeley, 1996.

\section{Knowledge representation:}

[29] WODTKE von Mark, Mind Over Media Creative Thinking Skills for Electronic Media Mcgraw-hill inc., 1993.

\section{Sign studies, sign science:}

[30] ECO, Umberto La guerre du faux, traduit de l'italien par Myriam Tanant Edition Grasset \& Fasquelle Le livre de poche - biblio - essais, 382 p., Paris, 1985.

[31] ECO, Umberto La Production des signes, (Ed. It. Indiana University Press 1976), Le livre de poche - biblio - essais, 126 p., 1992.

[32] ECO, Umberto Le signe, adapté de l'italien par Jean-Maire Klinkenberg, Edition Labor, Le livre de poche - biblio essais, 282 p., 1988.

\section{Sociology, pedagogy, psycology:}

[33] BRETON, Philippe, L’utopie de la communication - Le mythe du «village planétaire », Editions La Découverte, Col. Essais, 172 p., Paris, 1995.

[34] CADOZ, Claude, Les réalités virtuelles, Flammarion, Col. Dominos, 125 p., 1994. \{nouvelles technologies\}

[35] FLICHY, Patrice, Une histoire de la communication moderne - espace public et vie privée, Ed. La Découverte, Col. Histoire des Sciences, 281 p., Paris, 1991. \{histoire, nouvelles technologies, économie\}

[36] JOLIVALT, Bernard, La réalité virtuelle, Presses Universitaires de France, Col. Que sais-je?, 123 p., Paris, 1995. \{nouvelles technologies\}

[37] WATZLAWICK, P., HELMICK-BEAVIN, J., JACKSON, D., Une logique de la communication, aux Editions du Seuil, 286 p., Paris, 1972. 
(C) Ediciones Universidad de Salamanca.

Páginas mantenidas por Francisco Ignacio Revuelta Domínguez

y Luis González Rodero

webmrte@usal.es 